\title{
Improved assessment of wind-driven rain on building façade based on ISO standard with high-resolution on-site weather data
}

\author{
Hua Ge ${ }^{\mathrm{a}, *}$, Vincent Chiu ${ }^{\mathrm{b}}$, Ted Stathopoulos ${ }^{\mathrm{a}}$, Firouzeh Souri ${ }^{\mathrm{a}}$ \\ ${ }^{a}$ Department of Building, Civil and Environmental Engineering, Concordia University, Montreal, Quebec, Canada \\ ${ }^{\mathrm{b}}$ ROXUL Inc., Milton, Ontario, L9T 6W3, Canada
}

\section{A R T I C L E I N F O}

\section{Keywords:}

Wind-driven rain

Field measurements

Wind-tunnel measurements

Site wind conditions

Semi-empirical WDR model

Building façade

\begin{abstract}
A B S T R A C T
Wind-Driven Rain (WDR) is one of the major moisture sources that cause building envelope failures. The quantity and spatial distribution of WDR are important considerations for durable building envelope designs and are essential boundary conditions for hygrothermal modelling. Within a comprehensive research program of quantifying WDR exposure of buildings and the effectiveness of overhang on reducing WDR wetting, a six-storey building located in Vancouver, Canada was instrumented for field WDR measurements. One of the challenges in field WDR measurements is the validity of on-site wind measurements. The accurate measurements of on-site wind conditions are essential for correlating WDR on façade with on-site weather conditions and for generating the spatial distribution correction factor required in the semi-empirical WDR models. This paper focuses on discussing the procedure necessary for proper on-site wind measurements for quantifying WDR on façade based on field and wind-tunnel measurements. The proper procedure to calculate the spatial distribution correction factor, namely wall factor according to ISO standard, and its impact on the accuracy of the ISO model is also discussed. The accuracy of ISO model can be significantly improved by using more detailed wall factors calculated based on high-resolution on-site wind and rain measurements.
\end{abstract}

\section{Introduction}

Wind-driven rain (WDR) is one of the most important environmental loads and the main moisture source that affects the hygrothermal performance and durability of building envelopes (Kumaran and Sanders, 2008; Blocken and Carmeliet, 2004). The quantity and spatial distribution of WDR is affected by a wide range of parameters including wind speed, wind direction, rainfall intensity, wind angle, building geometry, location on building facades, and surrounding topography. WDR loads on facades are normally determined or estimated by measurements, semi-empirical correlations, and Computational Fluid Dynamics (CFD) modelling. Each approach has its advantages and limitations (Blocken and Carmeliet, 2004). Measurements have always been the primary tool for WDR study and provide the basic knowledge for understanding WDR, but they can be time consuming, expensive, and suffer from large errors (Blocken and Carmeliet, 2004, 2005a, 2006a; Blocken et al., 2009). Their use for the estimation of WDR load can be limited to the specific site where measurements were taken. These limitations motivated researchers to establish semi-empirical correlations between WDR on façades and the standard meteorological parameters. The semi-empirical correlations are developed on a theoretical basis with coefficients that are determined from measurements. The semi-empirical models estimate the WDR amount on a building façade by correlating available weather data i.e. wind speed, wind direction, and rainfall intensity collected at weather stations to the specific building site and façade location by introducing a number of correction factors to account for the specific terrain, topography, and building geometry, such as the procedure prescribed by ISO Standard 15927-3 (International Standard Organization (ISO), 2009). More detailed but more time-consuming alternative is to use CFD modelling. CFD models provide the WDR results on any particular building as a function of wind speed, wind direction, and horizontal rainfall intensity, however, its accuracy needs careful validation with high quality measurements (Blocken and Carmeliet, 2005b, 2007; Abuku et al., 2009). The importance of WDR has led to research efforts in this field in the past. In recent years, the application of numerical modelling (Abuku et al., 2009; Blocken and Carmeliet, 2006b; Huang and Li, 2010; Kubilay et al., 2013, 2014a, 2015a, 2017a; Pettersson et al., 2016) and efforts in col-

\footnotetext{
* Corresponding author.

Email address: hua.ge@concordia.ca (H. Ge)
} 
lecting high quality and high resolution measurements (Blocken and Carmeliet, 2005b; Nore et al., 2007; Kubilay et al., 2014b; Deb Nath et al., 2015; Krpan and Ge, 2014) have advanced our understanding of this complex phenomenon such as the effect of building geometry, geometrical details, and local weather conditions (Kubilay et al., 2015b, 2017b; Foroushani et al., 2013).

Because of their easy use and simplicity, semi-empirical correlations are still the most commonly used approaches for quantifying WDR load on building façades and are typically implemented in hygrothermal simulation programs. The accuracy of these semi-empirical models is affected by the correction factors such as the spatial distributions on facades, which are determined based on long-term field measurements. Studies showed that WDR estimated using these semi-empirical models deviated largely from field measurements (Kubilay et al., 2014b; Deb Nath et al., 2015; Chiu et al., 2015) and suffer from overestimation and the lack of variation with various building geometries and wind and rain conditions (Blocken and Carmeliet, 2010; Blocken et al., 2011). To improve the accuracy of semi-empirical models and provide datasets for validating CFD models, measurements on buildings with various geometries under different climatic conditions are valuable and essential for the advancement of research in WDR.

Within a comprehensive research program on quantifying WDR for mid-rise and high-rise buildings and the effectiveness of overhang, a number of buildings in three Canadian regions have been instrumented for WDR measurements (Ge et al., 2017a). One of the challenges in field measurements is the validity of on-site wind measurements. Ideally, a wind anemometer should be placed in front of the building in an open field to capture the approaching wind profile. However, due to the site limitation, it is often that wind anemometer has to be placed on the roof top and its height may also be restricted due to logistic limitation, therefore, the wind speed and wind direction measured at the anemometer height may be influenced by the building itself. The accurate measurements of on-site wind conditions are essential for correlating WDR on façade with the on-site weather conditions and for generating the spatial distribution correction factor required in the semi-empirical models. Therefore, correction of on-site wind measurements may be necessary. This paper focuses on discussing the procedure necessary for proper on-site wind measurements for quantifying WDR on façade based on field and wind-tunnel measurements. The proper procedure to calculate the spatial distribution correction factor, namely wall factor according to ISO standard, and its impact on the accuracy of the semi-empirical model is also discussed. A six-story building located in Vancouver, British Columbia, Canada is used as the case study building.

\section{Methods}

Both field measurements and wind-tunnel measurements have been carried out. The field measurements focus on quantifying WDR on façade and the effectiveness of overhang on reducing WDR wetting on façade with on-site wind and rain measurements. The wind-tunnel measurements focus on mean wind speed upstream, above and around the scaled building for verification of field wind measurements.

\subsection{Field measurements of wind-driven rain}

\subsubsection{Test building}

The test building is a six-story rectangular residential building with a low-sloped roof and a short parapet located in Vancouver, British Columbia (Fig. 1). The building sits atop an escarpment with the East façade facing the direction of the escarpment and is surrounded by 3-story residential buildings to its North and West and a highway to its East and South. The building is $39.2 \mathrm{~m}$ long, $15.2 \mathrm{~m}$ wide, and $19.8 \mathrm{~m}$ high. The building façades face the cardinal directions with one of the long façade facing the East, the prevailing wind direction. It is a fairly open site within a suburban setting, which makes it an ideal site for WDR studies. A customized retractable overhang structure is designed and installed on the East and North façade of the building to quantify the effectiveness of overhang.

\subsubsection{Instrumentation}

The parameters monitored include on-site weather conditions and WDR on façades. A weather station including an anemometer and a temperature and relative humidity probe is mounted on top of a tripod cross-arm that is $4.6 \mathrm{~m}$ above the mechanical room located on top of

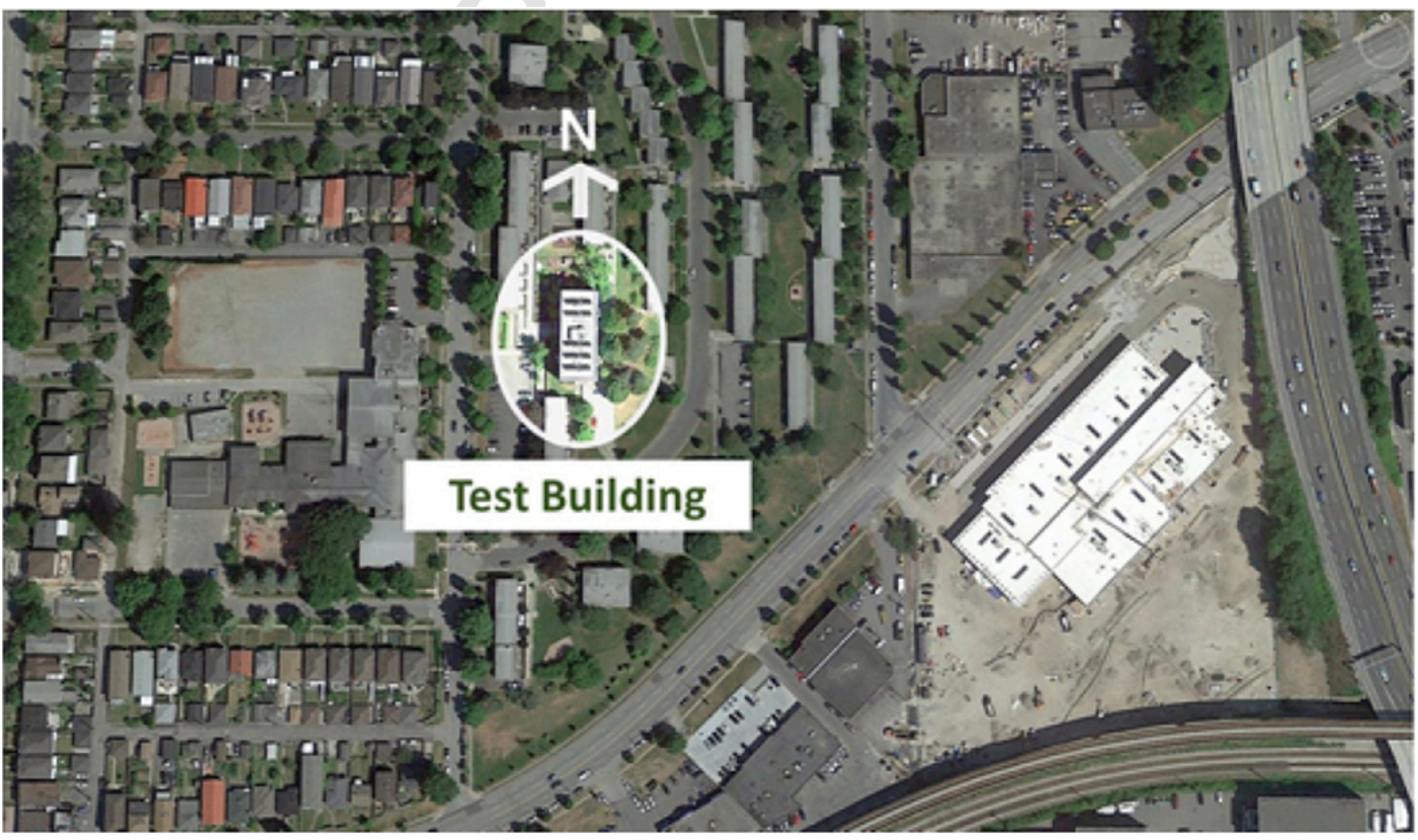

Fig. 1. Aerial view of the building site (from Google Maps). 
the main roof of the test building (Fig. 3). The anemometer can measure wind speed with a range of $0-50 \mathrm{~m} / \mathrm{s}$ with an accuracy of $\pm 0.2 \mathrm{~m} / \mathrm{s}$ or $1 \%$ of reading. It can measure wind direction within a range of $0-360^{\circ}$ with an accuracy of $\pm 0.3^{\circ}$. The horizontal rain gauge has a conical collection area ( $24.5 \mathrm{~cm}$ diameter) constructed of gold anodized spun aluminum. The resolution of the tipping bucket is $0.1 \mathrm{~mm} /$ tip with an accuracy of $1 \%$ up to $50 \mathrm{~mm} / \mathrm{h}$. The horizontal rain gauge is placed on the center of the main roof.

A total of 31 customized WDR gauges were installed on the building's façades at strategically selected locations based on the prevailing wind direction, building geometry and surroundings. Historical data collected from Environment Canada's National Climate Services were analyzed to identify the prevailing wind directions for the building site, which is from the East. Therefore, the majority of WDR gauges were installed on the East façade. To capture the spatial distribution of WDR on façade, the WDR gauges were placed at various locations horizontally and vertically with a focus at the top and corners to create a grid representing the typical wetting pattern on façade (Fig. 2). These driving rain gauges are aluminum plate-type gauges consisting of a square collection area, $30.5 \mathrm{~cm}$ by $30.5 \mathrm{~cm}$, i.e. $930.3 \mathrm{~cm}^{2}$. The rain gauge is designed with details to minimize measurement errors. The WDR gauge has a dual tipping-bucket mechanism with a resolution of $0.06 \mathrm{~mm} / \mathrm{tip}$. More detailed information about the experimental setup can be found in (Ge et al., 2017b).

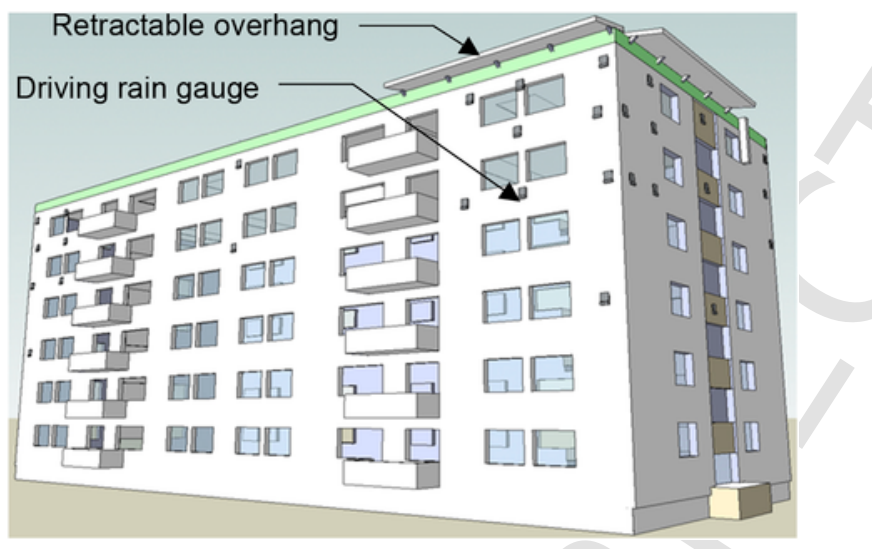

Fig. 2. Sketch up of the test building with the retractable overhang and wind-driven rain gauges on the East and North façades.

\subsubsection{Data collection and processing}

The anemometer, temperature and relative humidity probe, horizontal rain gauge, and WDR gauges are all connected to a central data logger, which is programmed to collect and store raw data every $5 \mathrm{~min}$. The wind data (wind speed and wind direction) is gathered at $1 \mathrm{~Hz}$ sampling frequency and averaged every $5 \mathrm{~min}$. The temperature and relative humidity are also averaged every $5 \mathrm{~min}$. The sum of tips is registered for the horizontal rain gauge and the WDR gauges every $5 \mathrm{~min}$. The data logger is connected to the internet via Ethernet, which allows the data to be collected remotely.

\subsection{Wind tunnel measurements}

Wind tunnel measurements were carried out in Concordia's atmospheric boundary layer (ABL) wind tunnel. To model the field, a suburban exposure has been created using roughness elements and a scaled down test building with its surrounding buildings.

\subsubsection{Model and exposure}

A 1:400 scale model of the test building and its surroundings within a $200 \mathrm{~m}$ radius have been fabricated and tested in the ABL wind tunnel (Fig. 4). The 1:400 scale is selected based on the surroundings and successful simulations at this scale of the most important variables of the atmospheric boundary layer under strong wind conditions carried out in this wind tunnel (Stathopoulos, 1984). The models are fabricated using extruded polystyrene foam insulation and glued to a particle board base. The test building in the field is located within a suburban environment, therefore, a similar exposure is simulated in the wind tunnel. To obtain a suburban wind profile, a mixture of roughness elements have been placed along the length of the test section of the tunnel. The roof of the wind tunnel was adjusted along the length of the test section to satisfy the condition of zero longitudinal pressure gradient for a suburban exposure. The test building model is $98 \mathrm{~mm}$ long, $38 \mathrm{~mm}$ wide, and $50 \mathrm{~mm}$ high. There is a mechanical room located on the center of the roof measuring $15 \mathrm{~mm}$ long, $13 \mathrm{~mm}$ wide, and $6 \mathrm{~mm}$ high.

\subsubsection{Wind velocity measurements}

A Series 100 Cobra probe was used to measure velocities in the wind tunnel. The Cobra Probe is a multi-hole pressure probe that provides dynamic, 3-component velocity and local static pressure measurements in real-time. The probe is capable of a linear frequency response from $0 \mathrm{~Hz}$ to more than $2 \mathrm{kHz}$ and is available in various ranges

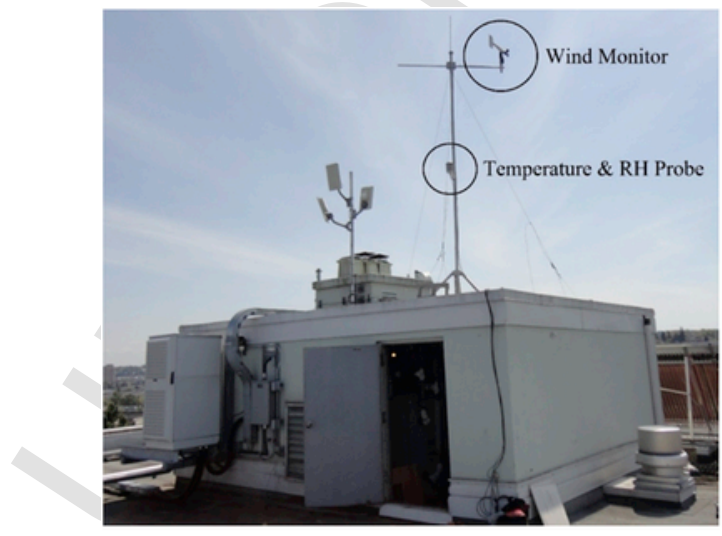

(a) Weather station mast on top of the mechanical room

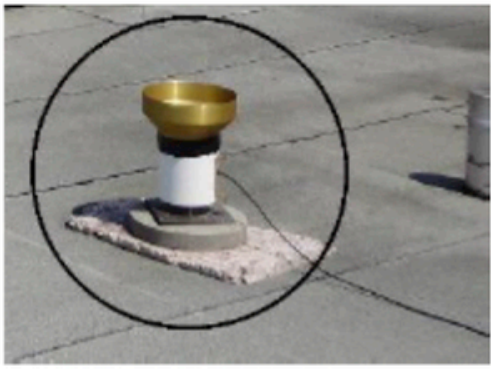

(b) Horizontal rain gauge

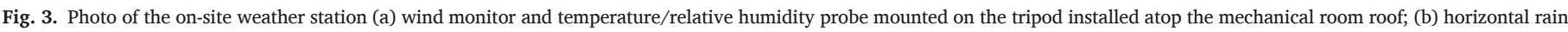
gauge on the main roof. 


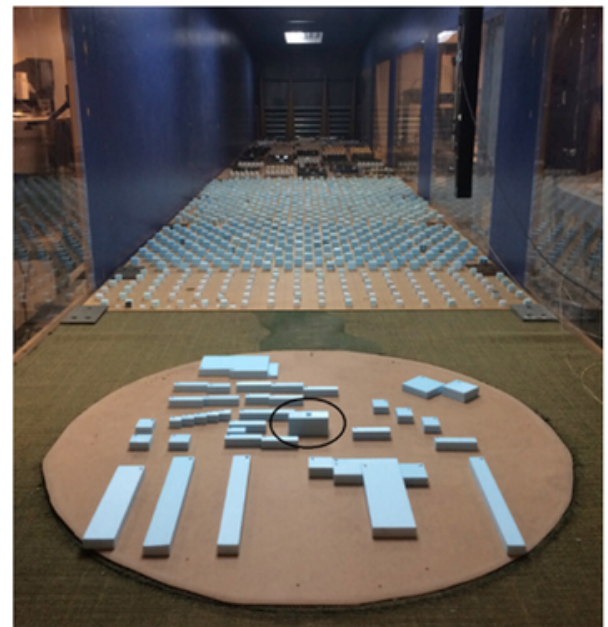

Fig. 4. The test building and surrounding buildings within a $200 \mathrm{~m}$ radius placed in $\mathrm{ABL}$ wind tunnel.

for use between $2 \mathrm{~m} / \mathrm{s}$ and $100 \mathrm{~m} / \mathrm{s}$. Although the probe comes pre-configured, the accuracy was verified by comparing the mean values measured by the Cobra Probe with the measurements of a pitot static tube mounted at the same location. In addition, the measurements were checked for repeatability for the wind profile above the mechanical room roof and in front of the East facade. The average percentage difference between the two tests were $1 \%$ and $6 \%$ for the wind profile above the roof and the East facade, respectively.

Suburban terrain The characteristics of the wind profile were determined by taking measurements along the vertical axis in the center of the turntable with no model(s) present. The velocities were normalized by simply dividing the mean velocities measured $(\bar{U})$ by the mean gradient velocity $\left(\bar{U}_{\mathrm{g}}\right)$ measured, as follows:

Normalized Velocity $=\frac{\bar{U}}{\bar{U}_{g}}$

The following suburban wind profile characteristics were generated in the wind tunnel:

1) Gradient height $\left(Z_{\mathrm{g}}\right)=80 \mathrm{~cm}$

2) Gradient wind speed $\left(U_{g}\right)=14.4 \mathrm{~m} / \mathrm{s}$

3) Mean speed exponent $(\alpha)=0.22$

The normalized mean velocities and turbulence intensities measured in the wind tunnel for the suburban configuration are shown in Fig. 5. The mean speed exponent of 0.22 obtained in the wind tunnel is close to the 0.25 value that is assigned to the field building.

Wind velocity around the building Once a suburban wind profile was successfully modeled in the wind tunnel, the building models with and without surroundings were placed in the wind tunnel and tested. Wind velocity measurements were taken upstream the test building (at $40 \mathrm{~m}, 80 \mathrm{~m}$ and $100 \mathrm{~m}$ away from the façade), in front of the test building's East and North façade, and above the mechanical room on the roof. Fig. 6 shows the measurement locations. There are 23 measurement points in front of the East facade (Figs. 6b) and 15 measurement points in front of the North façade (Fig. 6c), respectively. Limited by the probe profile, these measurement points are located $3.6 \mathrm{~m}$ away from the East façade and $1.2 \mathrm{~m}$ away from the North façade. A few more points are measured in addition to the locations where WDR

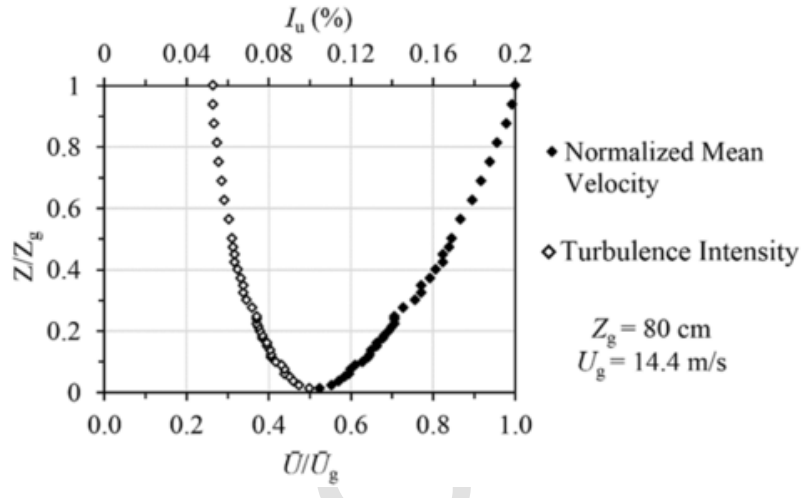

Fig. 5. Normalized mean velocity and turbulence intensity for a suburban exposure measured in the boundary layer wind tunnel.

gauges are installed, as shown in Fig. $6 \mathrm{~b}$ and c. Measurements were taken for two wind incidence angles, $0^{\circ}$ and $45^{\circ}$, to the East façade.

\section{Results and discussion}

\subsection{Wind measurements}

\subsubsection{Verification of on-site weather measurements}

To ensure that all of the equipment measuring the meteorological parameters are reliable, a comparison of wind speed and wind direction measured on-site was made with nearby weather stations. The local wind and rain measurements from nearby weather stations may deviate from the actual wind and rain experienced at the test site due to the local microclimate. The two nearby airport weather stations are Vancouver Sea Island station, which is located next to Vancouver International Airport and Pitts Meadows station, which is located at a regional airport East of the test building (Fig. 7).

Wind direction Fig. 8 shows the frequency of hourly wind direction for the three stations. The predominant wind direction is from the East for all three stations. The wind rose for the test building is similar to that of Vancouver Sea Island, however, there is a higher frequency of East-South-East winds present at the test building. Pitt Meadows receives a relatively higher frequency of northerly and southerly winds, which may be attributed to the valley leading to Pitt Lake to the North and the Fraser River to its South.

Wind speed The hourly wind speeds for the test building, Vancouver Sea Island and Pitt Meadows are shown in Fig. 9 for a period of a month. The wind speed at the test building has been converted to an "open country" exposure so that a direct comparison can be made with the two other "open country" exposures. The test building is primarily surrounded by two-to three-storey buildings, with no tall buildings in its immediate vicinity, therefore, is considered "suburban." Vancouver Sea Island and Pitt Meadows stations are both situated at airports, within a generally flat area, so both are considered "open country." The exposure types assigned to Pitt Meadows, Vancouver Sea Island, and the test building are shown in Table 1. There is a general agreement between the three stations, however, the influence of local microclimates is evident. The wind speed measured at the test building is similar to the wind speed measured at Vancouver Sea Island; both have a mean hourly wind speed of approximately $2.0-2.2 \mathrm{~m} / \mathrm{s}$, whereas the mean hourly wind speed at Pitt Meadows is approximately $1.4 \mathrm{~m} / \mathrm{s}$. The standard deviation is almost the same for both the test building and Vancouver Sea Island at approximately $1.0 \mathrm{~m} / \mathrm{s}$.

The wind speed and direction is of particular importance to WDR studies, therefore, a closer comparison of the on-site measured wind data is conducted. The comparison is composed of converting consecutive hours of high wind speeds with similar wind directions, from one 


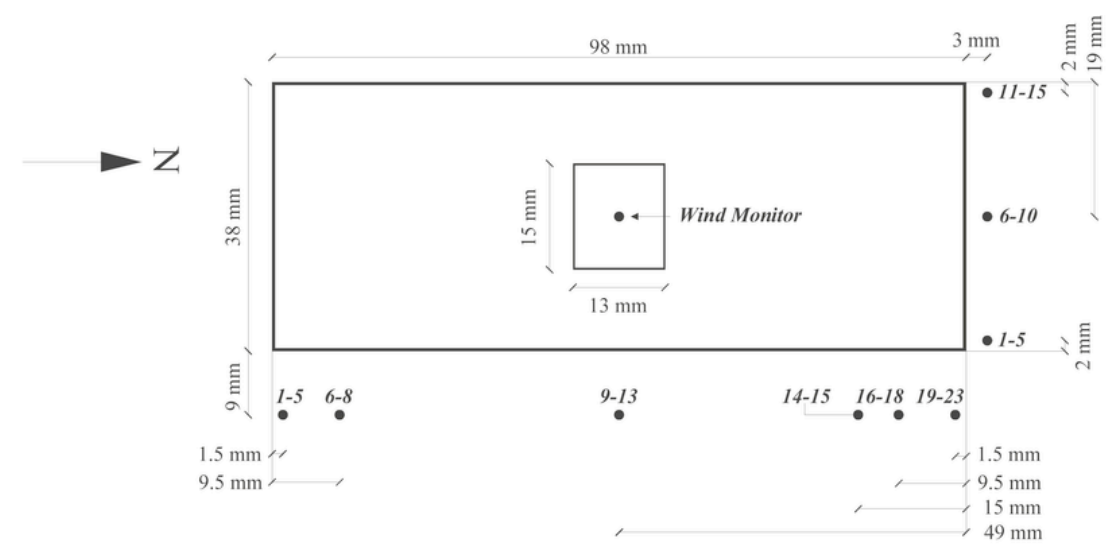

(a)

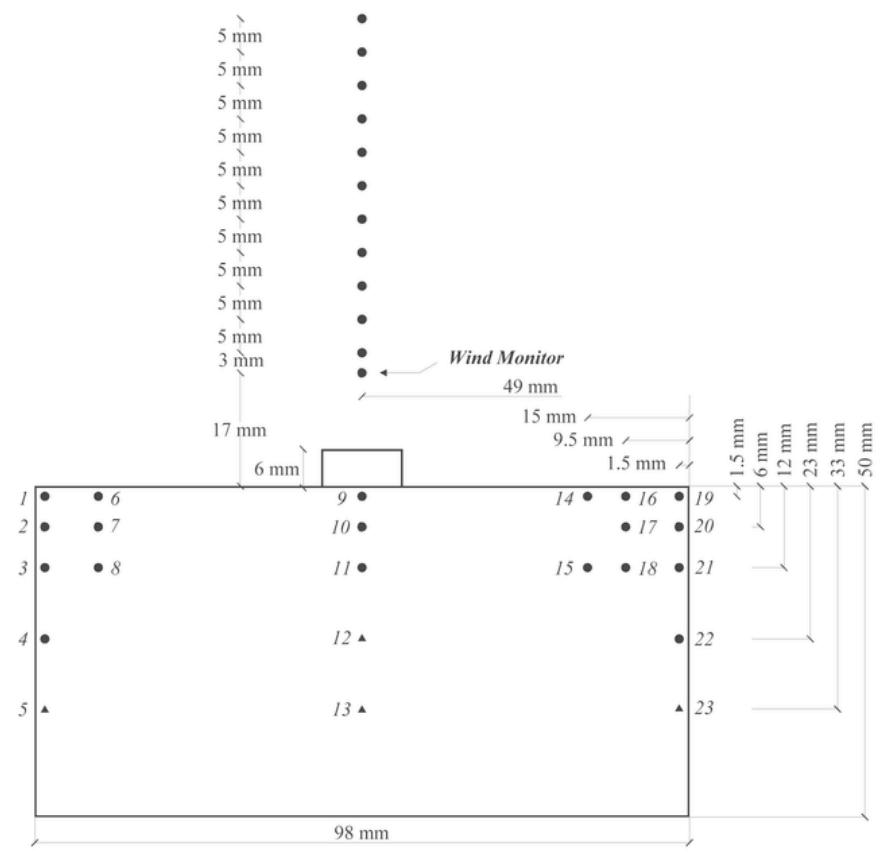

(b)

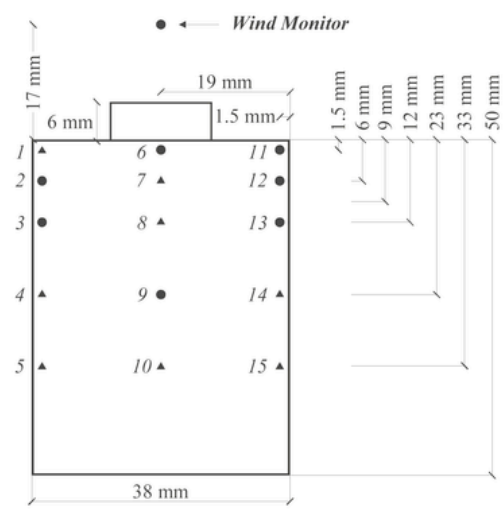

(c)

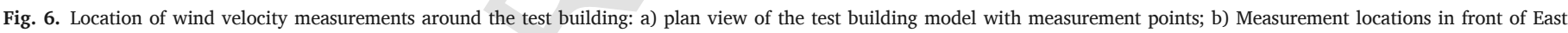
façade and above the mechanical room; and c) Measurement locations in front of North façade.

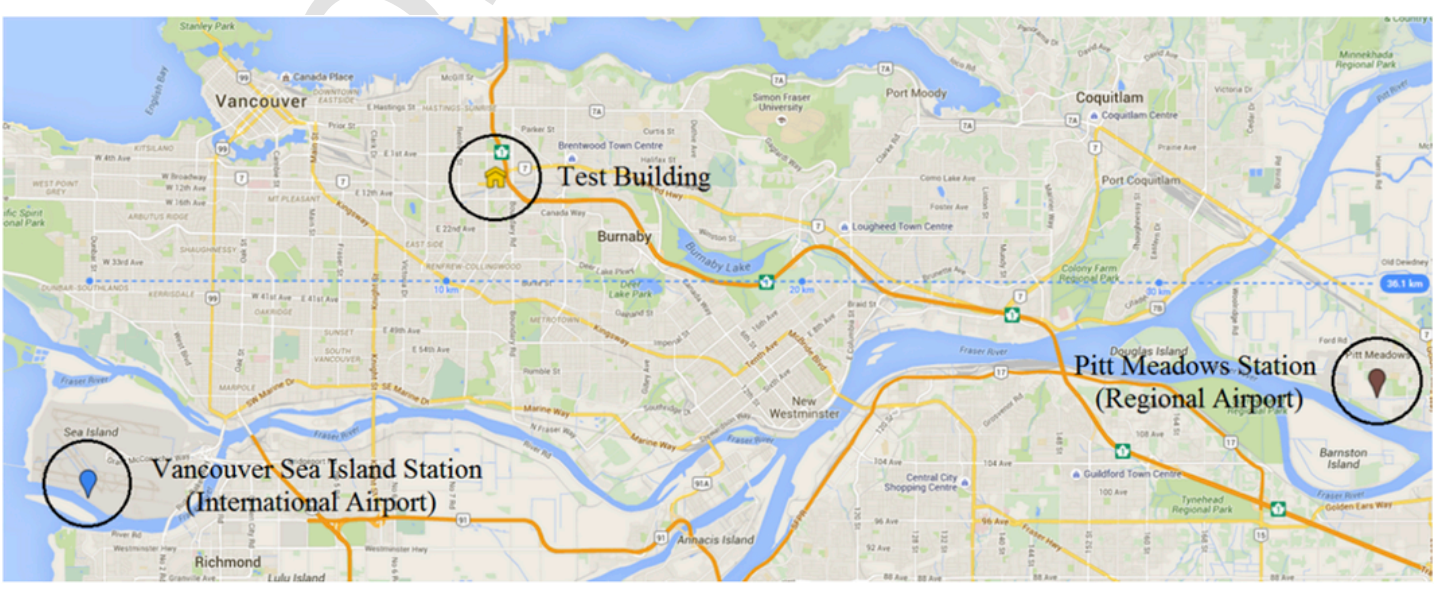

Fig. 7. Location of Pitt Meadows Regional Airport and Vancouver International Airport with respect to the test building (from Google Maps). 


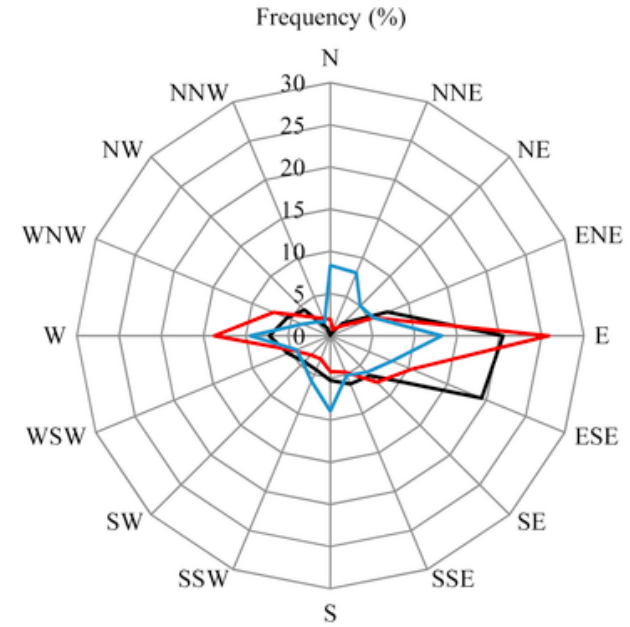

- Test Building — Vancouver Sea Island — Pitt Meadows

Fig. 8. Frequency of hourly wind direction $\left(^{\circ}\right)$ at the test building, Vancouver Sea Island and Pitt Meadows (Period from August 16, 2013 to June 30, 2015).

station to another, using the power law. The power law is considered a good representation of the variation of mean wind speed with height for strong winds over smooth terrain, and with the appropriate exponents, also applicable to cases of rough terrain. Thus, the wind data used for this analysis has been filtered, using only reference wind speeds greater than $5 \mathrm{~m} / \mathrm{s}$ from the reference weather station. This wind speed category generally corresponds to a neutral or slightly unstable atmosphere [30] giving a more reliable comparison between stations.

Since the wind direction is predominantly from East to West in the region, the wind speed measured at the test building has been converted to Vancouver Sea Island. Consecutive hours of high wind speeds measured at the test building ( $U_{\text {ref }}>5 \mathrm{~m} / \mathrm{s}$ ) have been considered and the wind direction between the two stations had to be approximately the same. Fig. 10 shows the wind speed measured at the test building converted to the exposure and elevation experienced at the airport for almost identical wind directions $\left(107^{\circ}-120^{\circ}\right.$ from the North). The cor- rected wind speed at the test building is in general agreement with the wind speed measured at Vancouver Sea Island for the same time period. This confirms that a suburban exposure exists at the test building site, at least for the area upstream of the East facade.

\subsubsection{Wind tunnel measurements}

Fig. 11 shows the vertical wind speed profiles above the mechanical room without test building present, with stand-alone building and test building with surroundings. For the stand-alone building, the presence of the building accelerates the wind speed at the wind anemometer location by about $12 \%$. When the surroundings are placed, the acceleration at roof top anemometer location is eliminated. Therefore, a power law correlation can be used to convert the roof top measured wind speed to wind speeds at other building heights. These wind speeds at different building heights are required for the calculation of wall factors, which will be discussed in section 3.2.1.

The normalized velocities near the East and North building facades, in the form of contour lines, with the wind approaching normal to the East facade $\left(0^{\circ}\right)$ are shown in Fig. 12 for the stand-alone test building and in Fig. 13 for the test building with its surroundings. Several observations are made for the East façade (Fig. 12a): (1) there is a symmetrical distribution of velocities across the facade, (2) the lowest velocities are encountered in the center of the facade and (3) the velocities increase from the center of the facade to the top and side edges of the facade. For the North facade (Fig. 12b), the velocities are highest at the windward edge and decreases towards the leeward edge.

As shown in Fig. 13, the influence of the surroundings on the test building is evident. The added "roughness" reduces the relative speed on the East facade (Fig. 13a), when compared to the East facade in the stand-alone model (Fig. 12a). The velocities on the North facade (Fig. 13b) are similar in pattern to the stand-alone model (Fig. 12b). However, there is a marked increase in velocities encountered across the North facade for the case with surroundings.

The normalized velocity contours for the stand-alone test building and test building with its surroundings with the wind approaching the East facade from the North-East $\left(45^{\circ}\right)$ are shown in Figs. 14 and Fig. 15 , respectively. For winds approaching from the North-East, the influence of the surrounding buildings on the East facade is apparent when

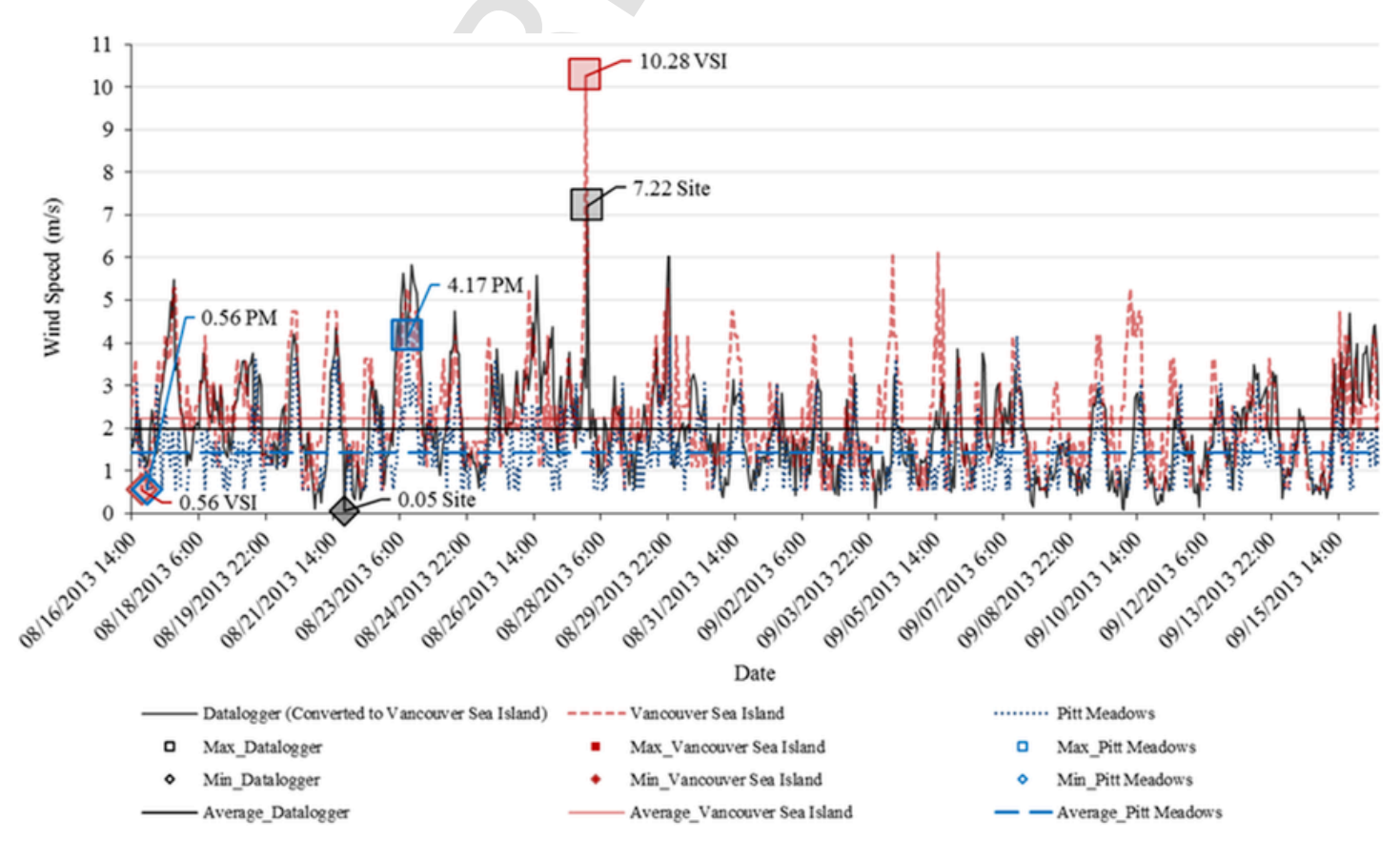

Fig. 9. Comparison of wind speed between test building, Vancouver Sea Island and Pitt Meadows weather stations. 
Table 1

Exposure type, elevation, reference height, gradient height, and mean speed exponent for Pitt Meadows, Vancouver Sea Island, and the test building.

\begin{tabular}{llll}
\hline Exposure & $\begin{array}{l}\text { Pitt } \\
\text { Meadows }\end{array}$ & $\begin{array}{l}\text { Vancouver Sea } \\
\text { Island }\end{array}$ & $\begin{array}{l}\text { Test } \\
\text { Building }\end{array}$ \\
\hline & $\begin{array}{l}\text { Open } \\
\text { country }\end{array}$ & Open country & Suburban \\
\hline $\begin{array}{l}\text { Elevation (m) } \\
\text { Reference Height, }\end{array}$ & 5 & 2.1 & 34 \\
$\begin{array}{l}Z_{\text {ref }}(\mathrm{m}) \\
\text { Gradient Height, }\end{array}$ & 10 & 10 & 26.8 \\
$\begin{array}{l}Z_{\mathrm{g}}(\mathrm{m}) \\
\text { Mean Speed }\end{array}$ & 300 & 300 & 400 \\
Exponent, $\alpha$ & 0.15 & 0.15 & 0.25 \\
\hline
\end{tabular}

comparing the stand-alone model (Fig. 14a) with the model with surroundings (Fig. 15a); the velocities are relatively lower when the surroundings are present. On the North facade, the velocities are similar for both the stand-alone building (Fig. 14b) and the building with surroundings (Fig. 15b), except near the top edge, where there is a drop in velocities for the case with surroundings.

\subsubsection{Comparison of wind tunnel measurements to field monitoring}

To verify the wind profile and the terrain roughness assumed for the test building, the normalized velocities measured by the wind monitor in the field were compared to the normalized velocities measured at the wind monitor location in the wind tunnel. This is simply the average velocity measured at the wind monitor location divided by the mean gradient velocity using equation (1).

In the field, the velocities measured by wind monitor were divided by gradient velocities obtained from two nearby airport weather stations: Pitt Meadows and Vancouver Sea Island. As listed in Table 1, the gradient height is $300 \mathrm{~m}$ at airport weather stations, the mean speed exponent is 0.15 and the reference height for wind data record is at $10 \mathrm{~m}$ above grade. At the building site, the gradient height for a suburban terrain is $400 \mathrm{~m}$ and the mean speed exponent is 0.25 , and the wind data record is at $26.8 \mathrm{~m}$ above the ground.

Hourly records with the highest wind speeds and the most similar wind directions between the test building and the airport stations were selected. Since the prevailing wind direction at the test building is from the East and South-East, it was possible to find records that fit the following hourly wind parameters:

1) $U_{\text {ref }}>5 \mathrm{~m} / \mathrm{s}$ and $\theta=90 \pm 10^{\circ}$ for winds coming from the East $\left(90^{\circ}\right)$.

2) $U_{\text {ref }}>5 \mathrm{~m} / \mathrm{s}$ and $\theta=135 \pm 10^{\circ}$ for winds coming from the South-East $\left(135^{\circ}\right)$.
The hourly data meeting the above criteria were verified to have relatively stable wind with small fluctuations of wind speed and direction within the hour by analyzing the 5-min data. Fig. 16 shows the wind speed and wind direction at a 5-min interval over $1 \mathrm{~h}$ recorded at the test building. The wind speed fluctuates from just over $4 \mathrm{~m} / \mathrm{s}$ to just under $8 \mathrm{~m} / \mathrm{s}$ within the hour with a mean wind speed of $5.8 \mathrm{~m} / \mathrm{s}$. The wind direction is fairly constant with an average of $97^{\circ}$ and a standard deviation of only $6^{\circ}$.

To perform a direct comparison between the field data and the wind tunnel data, the wind tunnel model was subjected to wind blowing from the East $\left(90^{\circ}\right)$ and from the South-East $\left(135^{\circ}\right)$, which is at $0^{\circ}$ and $45^{\circ}$ incidence angle. Fig. 17 compares the normalized velocities at the wind monitor location between the wind tunnel and the field, when placing a stand-alone test building in the wind tunnel. There is a good agreement between the wind tunnel and field measurements for both easterly and south-easterly winds when using Pitt Meadows as a reference station (Fig. 17a). The same could be said when using Vancouver Sea Island as a reference station (Fig. 17b), however, the normalized velocity for easterly wind in the field is somewhat lower than that measured in the wind tunnel. Fig. 18 compares the normalized velocities at the wind monitor location between the wind tunnel and the field, when the test building with its surroundings is tested in the wind tunnel. As expected, better agreements are achieved for both using Pitt Meadows and Vancouver Sea Island as reference stations. The case with surroundings is a better representation of the field than the stand-alone case.

These comparisons justify the assumption of a suburban terrain for the test building and also suggests that wind tunnel measurement is a viable approach to follow. Therefore, a power law wind profile with a suburban terrain mean speed exponent of 0.25 can be used to convert the wind speed measured on site at the roof top to wind speed at other building heights. This conversion of wind speed is required for calculating wind-driven rain amount on building façade using semi-empirical models such as ISO model and the calculation of wall factors.

\subsection{Wind-driven rain on façade}

\subsubsection{Calculation of wall factor}

Wall factor is defined as the ratio of the quantity of water hitting a wall to the quantity passing through an equivalent unobstructed imaginary vertical plane (International Standard Organization (ISO), 2009). It is a correction factor accounting for the complex interaction between wind, rain and the building and provides the spatial distribution of wind-driven rain on façades. As prescribed in ISO 15927-3 (International Standard Organization (ISO), 2009), equation (2) is used to calculate WDR in the airfield, i.e. through an imaginary unob-

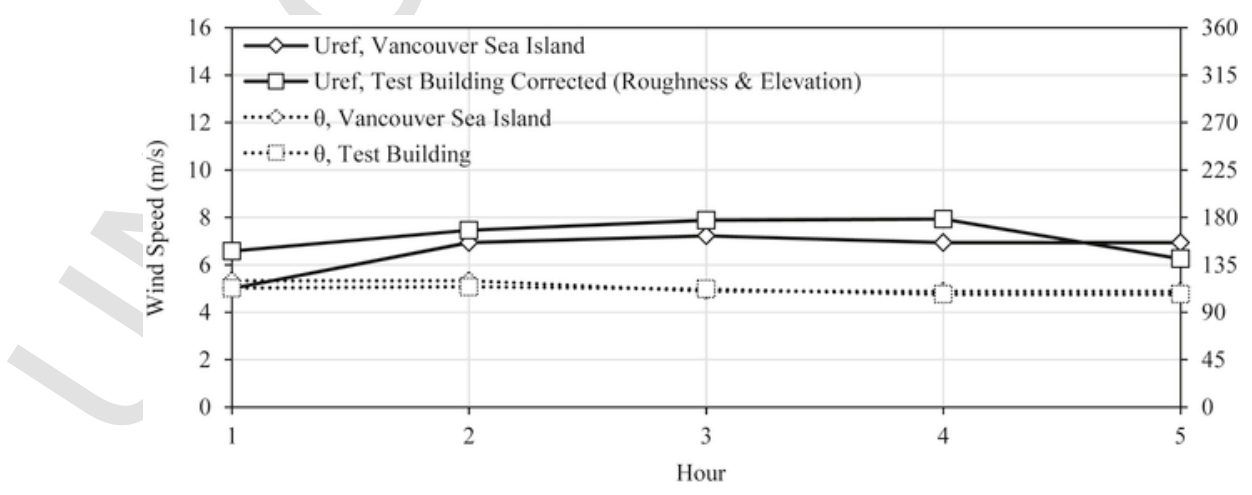

Fig. 10. Wind speed at the test building corrected to Vancouver Sea Island. (February 5th, 2014 from 14:00 to 18:00). 


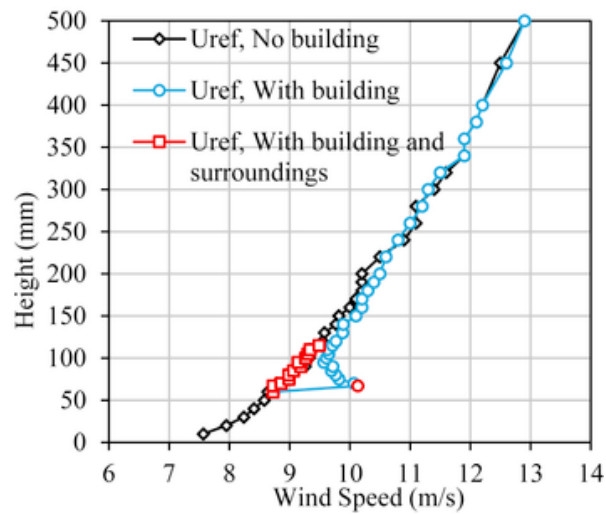

Fig. 11. Vertical wind speed profiles at test building location with and without surrounding.

structed vertical plane, while equation (3) is used to calculate WDR on the actual building façade by taking into account the influence of terrain roughness $\left(C_{R}\right)$, topography $\left(C_{T}\right)$, local obstruction $(O)$, and the spatial distribution $(W)$. Terrain roughness coefficient $\left(\mathrm{C}_{\mathrm{R}}\right)$ and topography coefficient $\left(\mathrm{C}_{\mathrm{T}}\right)$ are used to convert wind speed measured at airport weather station to the wind speed at building sites without the interaction of the building itself. Obstruction factor accounts for the shading effect of surroundings on the façade of interest. The common practice in wind engineering can be followed to determine $C_{T}$ and $C_{R}$, while wall factor (W), the correction factor taking into account the spatial distribution of WDR as a result of the complex interaction among wind, rain and the building, can only be determined based on measurements.

$$
\begin{aligned}
& I_{A}=\frac{2}{9} \Sigma \nu * R_{h}^{8 / 9} * \cos (D-\theta) \\
& I_{W A}=I_{A} * C_{R} * C_{T} * O * W
\end{aligned}
$$

Where, $v$ is the hourly mean wind speed in $\mathrm{m} / \mathrm{s}$ at the building height of interest, $R_{h}$ is the hourly rainfall in $\mathrm{mm}, D$ is hourly mean wind direction from North and $\theta$ is the wall orientation relative to North, where $\cos (D-\theta)$ is positive, i.e., all those occasions when the wind is blowing against the wall. The correction coefficients that are used to convert the airfield indices $\left(I_{A}\right)$ to wall indices $\left(I_{W A}\right)$ include terrain roughness coefficient $\left(C_{R}\right)$, topography coefficient $\left(C_{T}\right)$, obstruction factor $(O)$, and wall factor $(W)$.

One of the main purposes of WDR measurements is to provide this wall factor so that the actual WDR on building façade can be estimated based on weather data collected at airport weather station by applying the correction factors. When the on-site wind and rain data are available, the factors $C_{R}, C_{T}$, and $O$ can be taken as 1.0. As a result, the wall factor is calculated as the ratio of measured WDR $\left(R_{w d r}\right)$ to air field in-

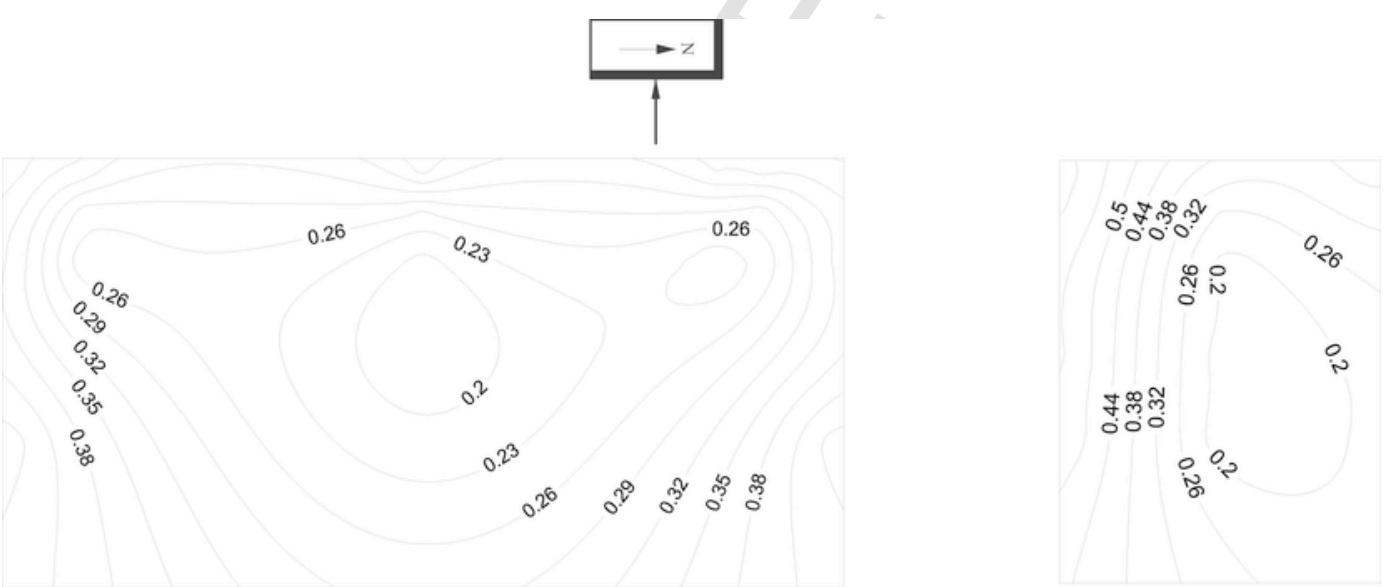

(a)

(b)

Fig. 12. Normalized velocities on the (a) East facade, (b) North facade.Stand-alone test building, $\theta=0^{\circ}$.

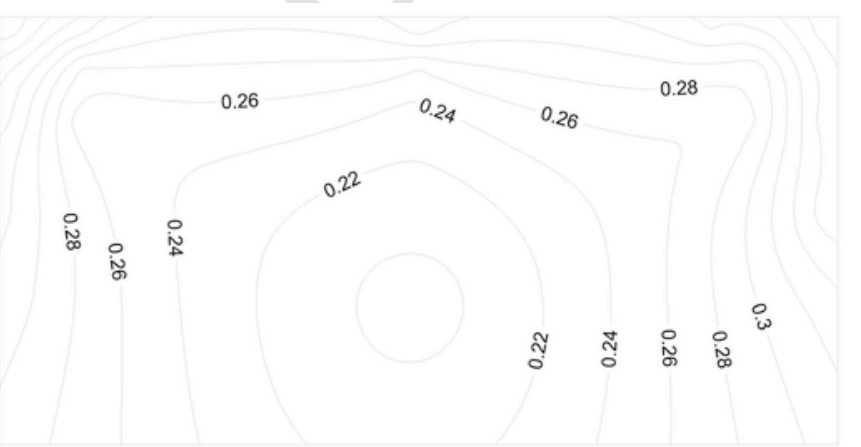

(a)

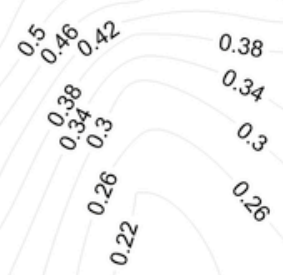

$\stackrel{0}{0} \quad \stackrel{\text { N }}{0}$

Fig. 13. Normalized velocities on the (a) East facade, (b) North facade.Test building with surrounding buildings, $\theta=0^{\circ}$. 


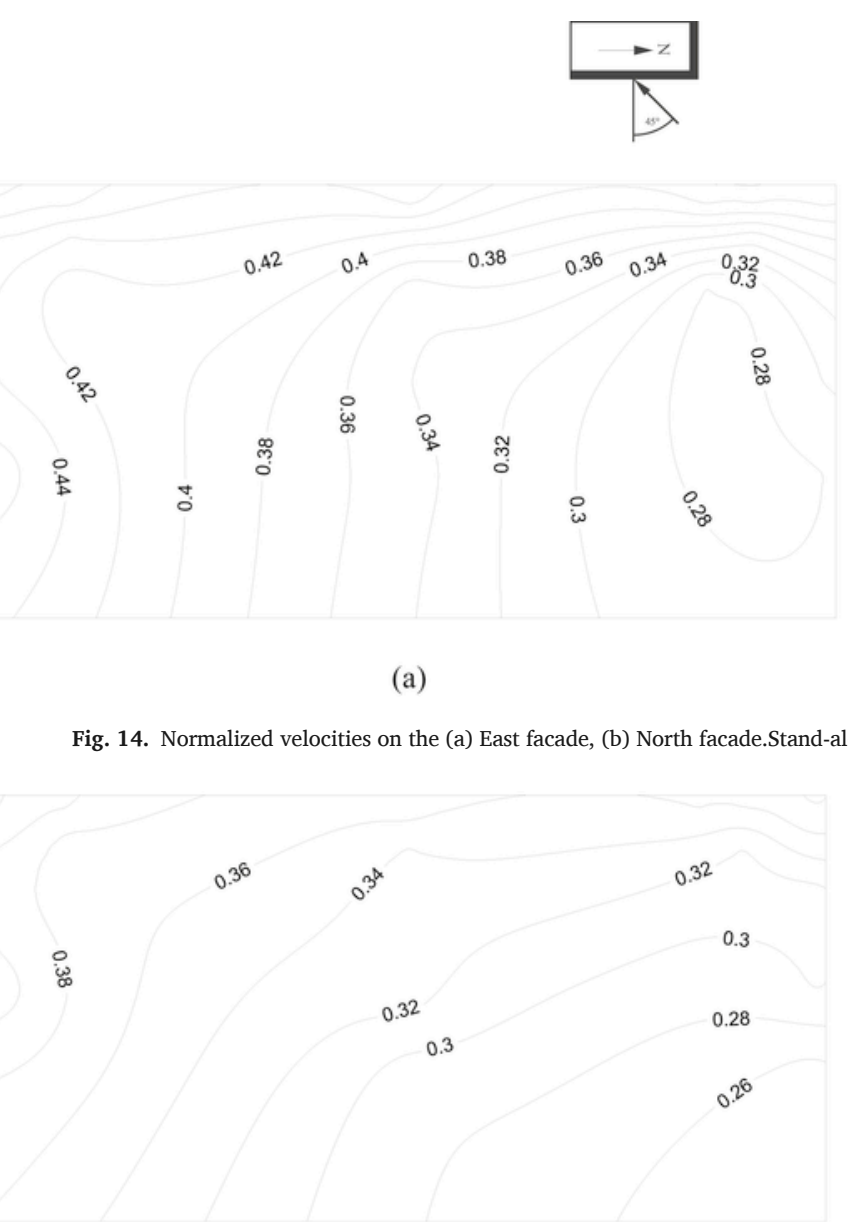

(a)

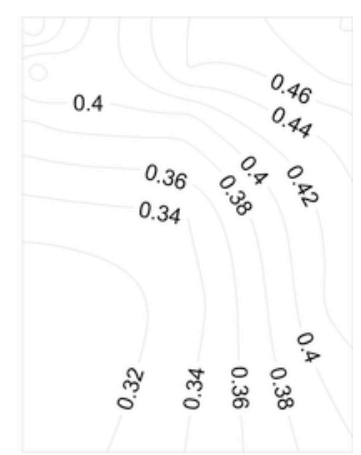

(b)

Fig. 14. Normalized velocities on the (a) East facade, (b) North facade.Stand-alone test building, $\theta=45^{\circ}$ (from North-East).

Fig. 15. Normalized velocities on the (a) East facade, (b) North facade.Test building with surrounding buildings, $\theta=45^{\circ}$ (from North-East).

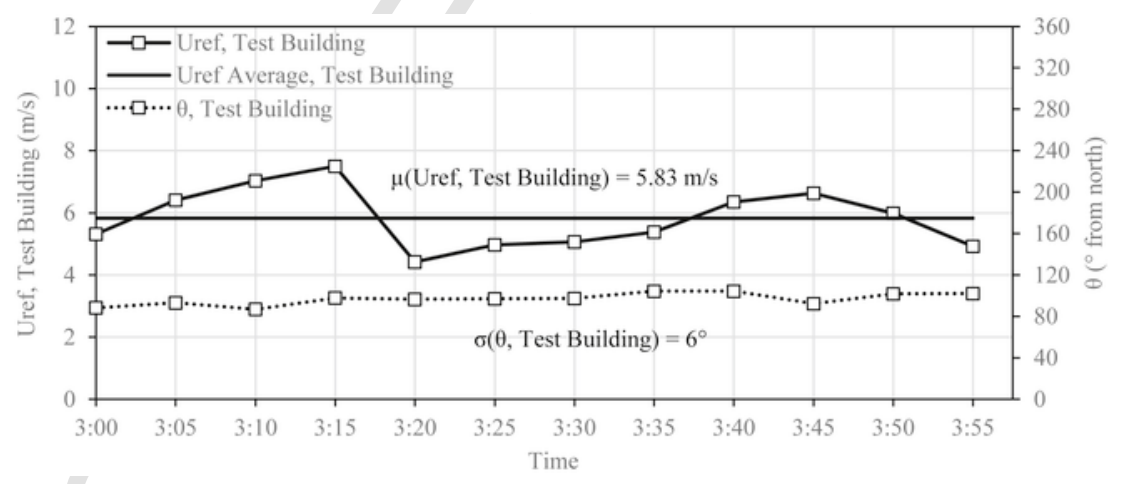

Fig. 16. Wind speed and wind direction at a 5-min interval recorded over $1 \mathrm{~h}$ at test building.

$\operatorname{dex}\left(I_{A}\right)$ (Eq. (4)).

$W=\frac{\Sigma R_{w d r}}{\frac{2}{9} \Sigma \nu * R_{h}^{8 / 9} * \cos (D-\theta)}$

The wind speed obtained at anemometer height has been converted to each driving rain gauge location using the power law correlation (Eq. (5)).

$$
\frac{V_{Z}}{V_{m}}=\left(\frac{Z}{Z_{m}}\right)^{\alpha}
$$

Where, $V_{z}$ and $V_{m}$ are the wind speeds at height $\mathrm{Z}$ and at wind monitoring height $Z_{m}$, respectively and $\alpha$ is the mean speed exponent.

Comparison between field and wind-tunnel, and field and airport measurements reported in the previous sections confirms a suburban terrain for the test building and validate the wind tunnel measurements. The on-site wind speed measured at the anemometer height can be used to calculate wind speed at other building heights following a 


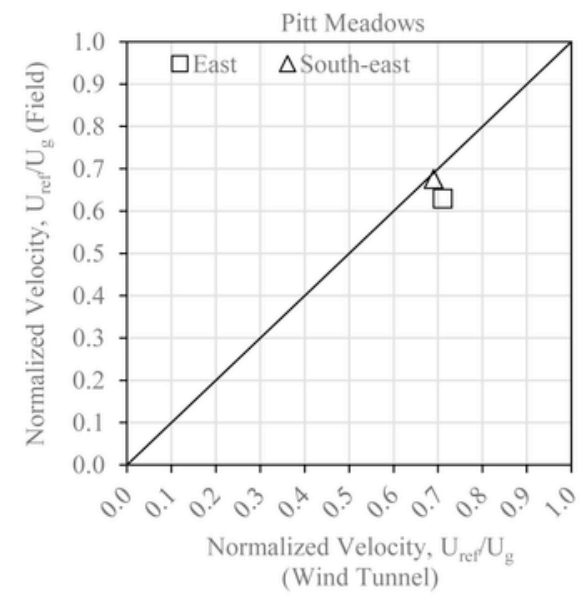

(a)

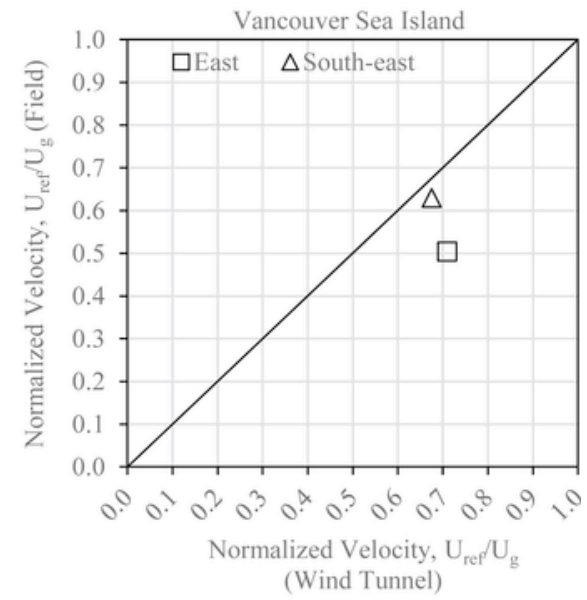

(b)

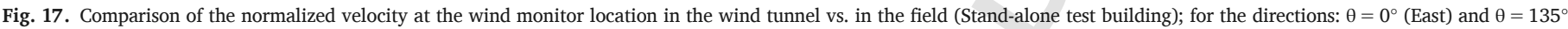
(South-East).

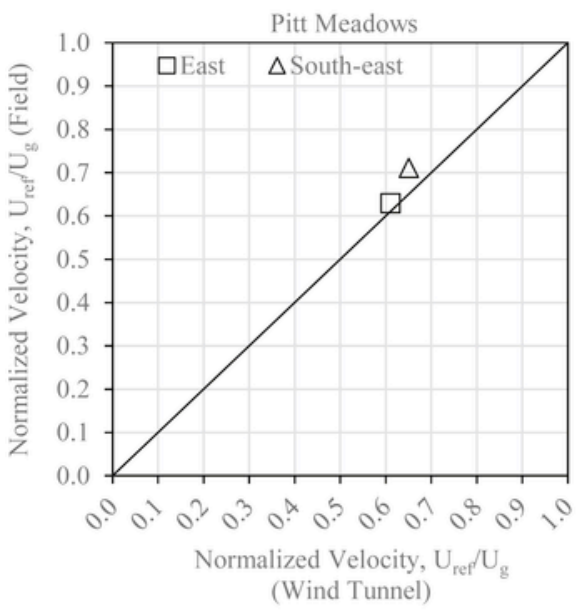

(a)

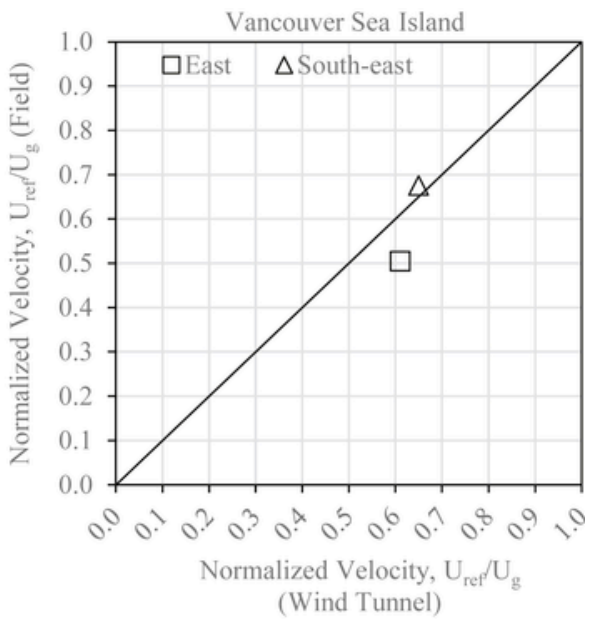

(b)

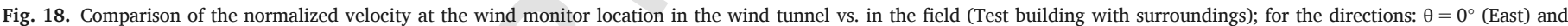
$\theta=135^{\circ}$ (South-East).

power law wind profile with a suburban terrain mean speed exponent. Indeed, an exponent of 0.25 has been used for the wall factor calculation.

Fig. 19 shows the wall factors on the East façade for the entire monitoring period without overhang. The ISO suggested wall factors are shown in gray, while the measured wall factors are shown in black. As shown in Fig. 19, there is a symmetrical distribution of wall factors across the East facade since the prevailing wind direction during rain hours is from the East. The measured wall factors on the East facade decreases from the top of the facade to the bottom and from the side of the facade to the center. The highest wall factors encountered on the East facade are at the corner gauges ES1 and EN1, with values of 0.52 and 0.49 , respectively; ISO suggests a wall factor of 0.50 at these locations. In general, the ISO suggested wall factors are an overestimation of the wall factors across the East facade; although they provide a good estimation at the top corners and at the third row of gauges, except for the center gauge EC2. There are significant overestimations at the second row of gauges when compared to the measured values.

\subsubsection{Comparison between WDR measured and estimated by ISO model}

The amount of WDR on building façades is estimated using the ISO standard 15927 (International Standard Organization (ISO), 2009) and the estimated amount is compared to measurements. Hourly wind speed and wind direction data obtained from Vancouver Sea Island weather station for the monitoring period are used for the calculation. As hourly rainfall data for the monitoring period is not available at the meteorological station, hourly rainfall intensity measured onsite is used for calculating the WDR. Roughness coefficient $\left(C_{R}\right)$ can be calculated by the following equations:

$$
\begin{aligned}
& C_{R}=K_{R} \ln \left(z / z_{0}\right) \quad \text { for } z \geq z_{\min } \\
& C_{R}=K_{R} \ln \left(z_{\min }\right) \quad \text { for } z<z_{\min }
\end{aligned}
$$

where $z$ is the height above ground. Values of $K_{R}, z_{0}$ and $z_{\min }$ are 0.22 , 


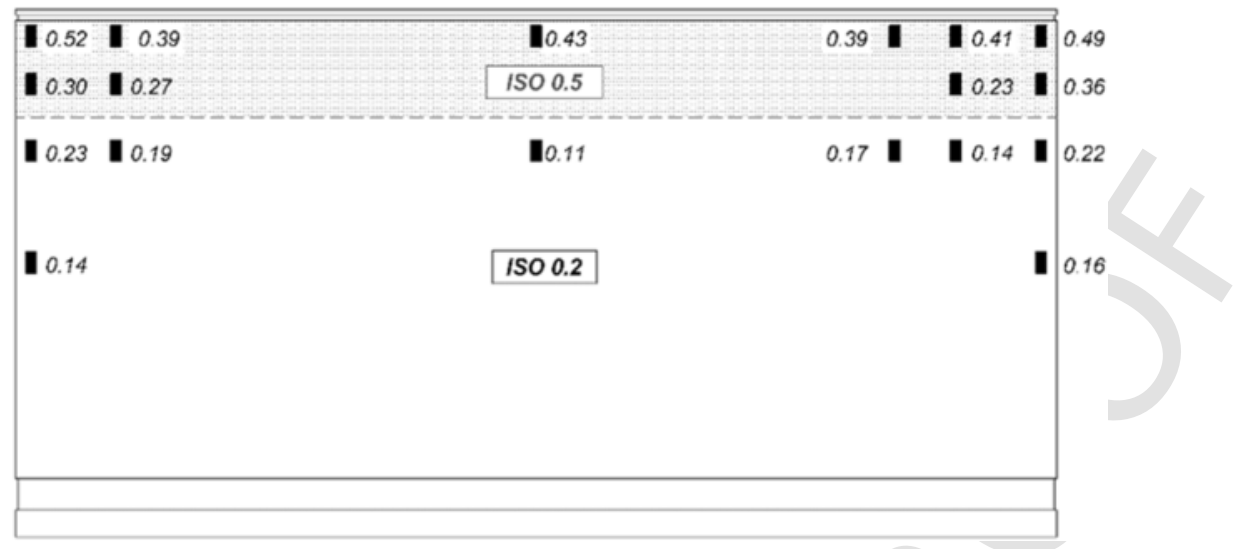

Fig. 19. Wall factors (ISO recommended vs measured) on the East façade during the period without overhang.

0.3 and 8 for suburban area, respectively. Topography coefficient $\left(C_{T}\right)$ is taken as 1.0, Obstruction factor $(O)$ is taken as 1.0, and wall factor $(W)$ is 0.5 for top $2.5 \mathrm{~m}$ and 0.2 for the remainder, following the ISO standard.

Fig. 20 shows the comparison between the measured WDR and the WDR calculated using the ISO semi-empirical model. Note that the WDR amount has been calculated for the entire monitoring period with all approaching wind angles. The ISO model overestimates the WDR amount at $93 \%$ of the monitored locations (26 out of 28 ) and slightly underestimates for the remaining $7 \%$ ( 2 out of 28 ) locations. The overestimation can be as high as more than two times for locations typically at $2.4 \mathrm{~m}$ below the roofline (EN6, ES2, EC2, NE1).

The significant WDR overestimation by the ISO model is mainly due to the values of wall factors suggested by the ISO standard, which are generally greater than those measured and lack of variation over the façade surface, as shown in Fig. 19. The ISO standard suggests only a constant wall factor, 0.5 for the top $2.5 \mathrm{~m}$ and 0.2 the reminder part of the façade. However, measurements show that depending on the geometry of the building, wall factors are typically smaller than 0.2 for locations below $2.5 \mathrm{~m}$, while within the top $2.5 \mathrm{~m}$ at some locations, such as top corners, wall factors are higher than 0.5 and at other locations such as the center of the façade, wall factors are lower than 0.5. Therefore, the use of higher wall factors leads to higher estimated WDR.

WDR amount is also calculated using ISO model with measured wall factors, while the other three correction factors used are the same. As shown in Fig. 20, the use of measured wall factors improved the WDR predictions significantly and the differences between predictions and measurements are reduced to about $21 \%$ for the East façade, while the use of measured wall factors increased the discrepancy for some of the locations on North façade.

\subsubsection{Further investigation of discrepancies}

Further analysis is carried out to investigate the sources of discrepancies that still exist between measured WDR and calculated WDR using measured wall factors.

As shown in equation (3), the ISO calculation involves the airfield driving rain index and correction factors. When on-site wind speed and wind direction at specific façade locations are interpolated based on wind conditions recorded at airport weather station, the assumption of terrain roughness, topography, and surroundings may introduce errors. Given that the calculated wall factors are based on site measured wind speed, wind direction, rainfall intensity measurements, the influence of local topography and obstructions has been taken into account. The terrain category has been verified as discussed in section 3.1. The remaining discrepancies could be attributed to the difference in wind conditions between site and weather station. On-site measurements show that the converted wind speed and wind direction are slightly different than airport data although they agree well in general. The assumption of a constant mean wind speed exponent in the power law correlation converting wind speed from the airport to the building site is valid for stable atmospheric condition, while it is highly influenced by atmospheric stability, wind speed and land features [31]. The on-site wind and rain measurements are taken at 5-min intervals and then converted to hourly average. The wall factors calculated based on hourly average data may be different than those calculated based on 5-min data, which will influence the calculated WDR amount. Other sources of errors could be the simplification of cosine projection to account for the wind incidence angle and the constant value of wind-driven rain coefficient of 2/9 used in the calculation of airfield wind-driven rain and wall factor (equations (2) and (4)).

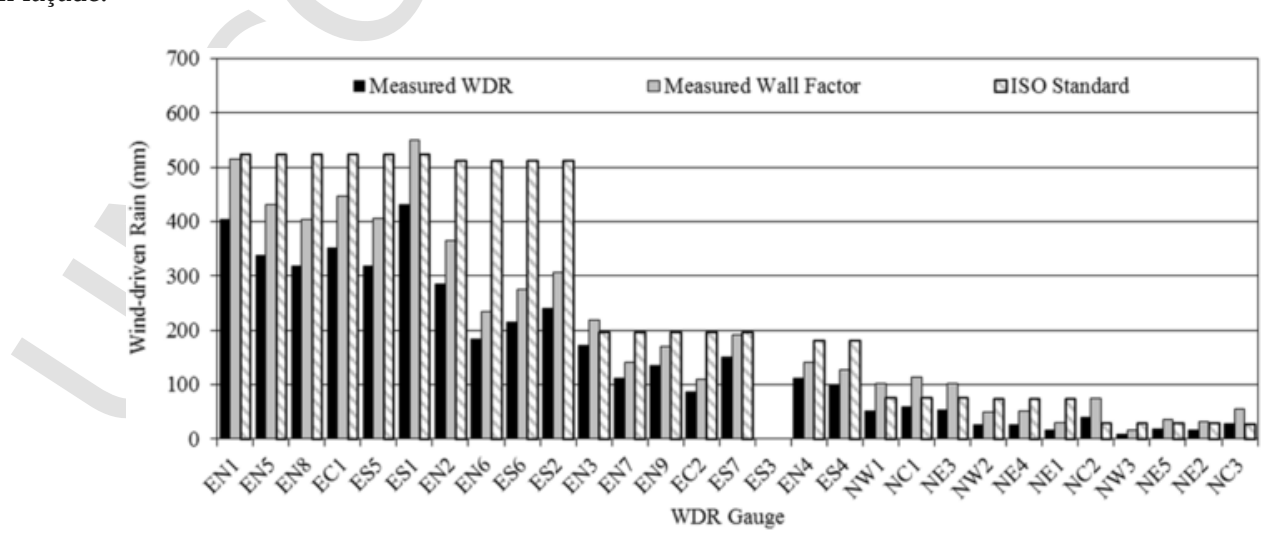

Fig. 20. Comparison of WDR between measurements and estimation using ISO model with ISO suggested and measured wall factors. 
Analysis was carried out to investigate the influence of wind-driven rain coefficient, the exponent of rainfall intensity (8/9 vs 1 ), terrain roughness exponent $(0.25$ vs 0.22 ), and wind speed profile (power low vs logarithmic). The effect of these factors was found to be small when using hourly average data. Therefore, to further investigate the remaining discrepancy, two aspects were taken into account: 1) difference in hourly wind speed and wind direction between airport and site; and 2) wall factors calculated using 5-min data.

\subsubsection{Difference in hourly wind speed and wind direction As shown in}

Fig. 8, the wind direction during rain agrees between Vancouver Sea Island and the site generally well but there are also slight differences. The frequency of wind from the East at the airport is greater than that on-site. In some instances, the airport data shows that wind approaching the East façade, while on site data shows that the actual wind is not approaching the East façade, which will result in over-estimation of driving rain on the East façade based on the airport wind direction. Therefore, to eliminate the error from the difference in wind direction between airport and site, the measured data was filtered to include only the period during which the wind approaches the façade and this period is applied to filter airport data as well. As shown in Table 2, the discrepancy is reduced from $21 \%$ to $19 \%$ for the East façade with filtered wind direction. The small improvement for the East façade (2\%) is due to the fact that most of the time the wind comes from the East. The improvement for the North façade is from $94 \%$ to $-47 \%$.

Although it has been verified that a suburban terrain assumption with a constant mean speed exponent of 0.25 is reasonable for the test building, discrepancy exists between on-site measurements and converted wind speed based on airport data given that the change over the course with terrain, topography, etc. (Fig. 9). As shown in Fig. 10, under stable conditions, the agreement is generally good, a 10-15\% difference can still be observed. The comparison between measured and converted wind speed for more periods is carried out. In general, the converted wind speed at anemometer height based on airport data is higher than the measured value. An average correction factor $(0.81)$ is calculated over the monitoring period to compensate this difference. Then this correction factor is applied to the airport wind speed for the calculation of airfield driving rain index. As shown in Table 2, with this wind speed adjustment, the discrepancy is reduced from $21 \%$ to $-2.0 \%$ for the East façade. The improvement for the North façade is from $94 \%$ to about $40 \%$ (not listed in Table 2). Note that only the results for East façade are shown in Table 2 as the example. Then the wind speed correction factor applies to filtered wind direction. The combination of these two adjustments result in a reduction of discrepancy from $21 \%$ to $-3.7 \%$ for the East façade and from $94 \%$ to $-27 \%$ for the North façade. Note that the errors reported here are the average of all rain gauge locations.

3.2.3.2. 5-Min vs hourly average weather data Equation (4) is applied to 5 -min data to calculate the wall factors first and these wall factors are used for the WDR calculation on façade based on hourly data from the airport without adjustments of wind direction and wind speed. As shown in Table 2, the use of 5-min data results in a reduction of discrepancy from $21 \%$ to less than $-1 \%$ for the East façade. The reduction of discrepancy for the North façade is from $94 \%$ to $-1.5 \%$ (not listed in Table 2). The use of high-resolution measurements in wind and rain compensate greatly for the difference in wind speed and wind direction between airport and the site. Fig. 21 shows the comparison between measured WDR, calculated WDR with correction for wind direction and speed, and calculated WDR with wall factors based on 5 -min measurements.

\subsection{Discussion}

As shown in Fig. 20, with measured wall factors, there is still about $21 \%$ difference between measured WDR and calculated WDR using ISO model for the East façade and up to 94\% difference for the North façade. In these calculations, hourly wind speed and wind direction from airport data, and measured wall factors based on hourly averaged on-site wind speed and wind direction are used. Based on the analysis, the main contributor to the discrepancy between measurements and calculations is from the difference in wind speed and wind direction between airport weather station and the site. This difference can be accounted for by either correcting the hourly airport data through adjustment of wind speed and filtering the wind direction with wall factors calculated using hourly averaged wind data or by using 5 -min measured data to calculate wall factors without adjustment of the hourly wind data from the airport. Through correcting the hourly wind data from the airport, the error can be reduced to $2 \%$ for the East façade and the improvement is achieved mainly by adjusting the wind speed. For the North façade, filtering the wind direction and adjusting wind speed has similar result, discrepancies reduced to about $40 \%$ but in opposite direction, while the combination of these two reduces the discrepancy to $27 \%$. The use of 5-min based wall factors significantly reduces the discrepancy between measurements and calculations for both façades, to less than $1 \%$ for the East façade and to $3.7 \%$ for the North façade.

When semi-empirical models such as ISO is used, available data include weather data from the airport station, building site location and building geometry. On-site wind and rain data are typically not available. Therefore, the correction of hourly weather data on the airport data is not possible without knowing the on-site wind conditions. Given that wall factors calculated using 5-min data have consistent and best results for both façades, at least for this case study building, it is recommended to carry out wind and rain measurements and report wall factors at higher resolution.

\section{Conclusions}

WDR measurements on the façades of a six-story building located in Vancouver, Canada have been carried out to study the effectiveness of overhang. The on-site wind speed and wind direction is measured at $4.5 \mathrm{~m}$ above the mechanical room rooftop of the building. The on-site rainfall intensity is measured using a tipping bucket rain gauge placed on the main roof. Twenty-nine customized driving rain gauges are placed on the East and North façade to measure the WDR on façade.

The wind conditions measured on-site are used to generate the WDR spatial distribution factor required in the semi-empirical WDR model, which requires the proper wind profile assumption according to the terrain roughness. To verify the on-site wind speed measurements and the assumption of a suburban terrain, on-site wind measurements are compared with nearby airports data and wind-tunnel measurements on a scaled model with and without surroundings. The main findings are:

- Wind tunnel measurements showed that at the anemometer height wind speed follows the power law profile and the wind tunnel measurement agrees well with field measurements when modeled with surroundings.

- The comparisons validated the assumption of a suburban terrain for the test building and validate the wind tunnel measurements.

- The on-site wind speed measured at the anemometer height can be used to calculate wind speed at other building heights following a 
Table 2

Comparison between measured WDR and calculated WDR on the East façade with wind speed and wind direction corrections and wall factors calculated using 5-min measured dat

\begin{tabular}{|c|c|c|c|c|c|c|c|c|c|c|c|}
\hline \multirow[t]{2}{*}{ Gauges } & \multirow[t]{2}{*}{ Measured (mm) } & \multicolumn{2}{|l|}{ Base case } & \multicolumn{2}{|l|}{ WD correction } & \multicolumn{2}{|l|}{ WS Correction ${ }^{\mathrm{a}}$} & \multicolumn{2}{|c|}{ Combined WD and WS correction } & \multicolumn{2}{|c|}{ With wall factors based on 5-min data } \\
\hline & & $\begin{array}{l}\text { Calculated } \\
(\mathrm{mm})\end{array}$ & Error (\%) & Calculated (mm) & Error (\%) & Calculated (mm) & Error (\%) & Calculated (mm) & Error (\%) & Calculated (mm) & Error (\%) \\
\hline EN1 & 402.30 & 486.31 & 20.88 & 478.48 & 18.94 & 393.91 & -2.09 & 387.56 & -3.66 & 399.23 & -0.76 \\
\hline EN5 & 337.66 & 408.04 & 20.84 & 401.47 & 18.90 & 330.51 & -2.12 & 325.19 & -3.69 & 334.98 & -0.79 \\
\hline EN8 & 316.99 & 383.08 & 20.85 & 376.91 & 18.90 & 310.29 & -2.11 & 305.30 & -3.69 & 314.49 & -0.79 \\
\hline $\mathrm{EC} 1$ & 350.45 & 423.18 & 20.75 & 416.37 & 18.81 & 342.78 & -2.19 & 337.26 & -3.76 & 347.41 & -0.87 \\
\hline ES5 & 318.71 & 384.93 & 20.78 & 378.73 & 18.83 & 311.79 & -2.17 & 306.77 & -3.75 & 316.01 & -0.85 \\
\hline ES1 & 430.01 & 519.51 & 20.81 & 511.14 & 18.87 & 420.80 & -2.14 & 414.02 & -3.72 & 426.49 & -0.82 \\
\hline EN2 & 285.38 & 345.37 & 21.02 & 339.81 & 19.07 & 279.75 & -1.97 & 275.24 & -3.55 & 283.53 & -0.65 \\
\hline EN6 & 184.41 & 222.73 & 20.78 & 219.14 & 18.83 & 180.41 & -2.17 & 177.50 & -3.75 & 182.85 & -0.85 \\
\hline ES6 & 215.91 & 260.52 & 20.66 & 256.32 & 18.72 & 211.02 & -2.27 & 207.62 & -3.84 & 213.87 & -0.94 \\
\hline ES2 & 240.38 & 290.53 & 20.86 & 285.85 & 18.92 & 235.33 & -2.10 & 231.54 & -3.68 & 238.51 & -0.78 \\
\hline EN3 & 172.38 & 208.68 & 21.06 & 205.32 & 19.11 & 169.03 & -1.95 & 166.30 & -3.52 & 171.31 & -0.62 \\
\hline EN7 & 111.82 & 134.93 & 20.67 & 132.76 & 18.72 & 109.29 & -2.26 & 107.53 & -3.84 & 110.77 & -0.94 \\
\hline EN9 & 134.51 & 162.79 & 21.02 & 160.17 & 19.08 & 131.86 & -1.97 & 129.74 & -3.55 & 133.64 & -0.64 \\
\hline $\mathrm{EC} 2$ & 86.42 & 104.39 & 20.79 & 102.71 & 18.84 & 84.55 & -2.16 & 83.19 & -3.74 & 85.70 & -0.84 \\
\hline ES7 & 150.27 & 181.33 & 20.67 & 178.41 & 18.73 & 146.88 & -2.26 & 144.51 & -3.83 & 148.86 & -0.94 \\
\hline EN4 & 111.52 & 134.31 & 20.43 & 132.14 & 18.49 & 108.79 & -2.45 & 107.04 & -4.02 & 110.26 & -1.13 \\
\hline ES4 & 100.39 & 120.79 & 20.32 & 118.84 & 18.38 & 97.84 & -2.54 & 96.26 & -4.11 & 99.16 & -1.23 \\
\hline
\end{tabular}

a A correction factor of 0.81 is used based on the analysis. 


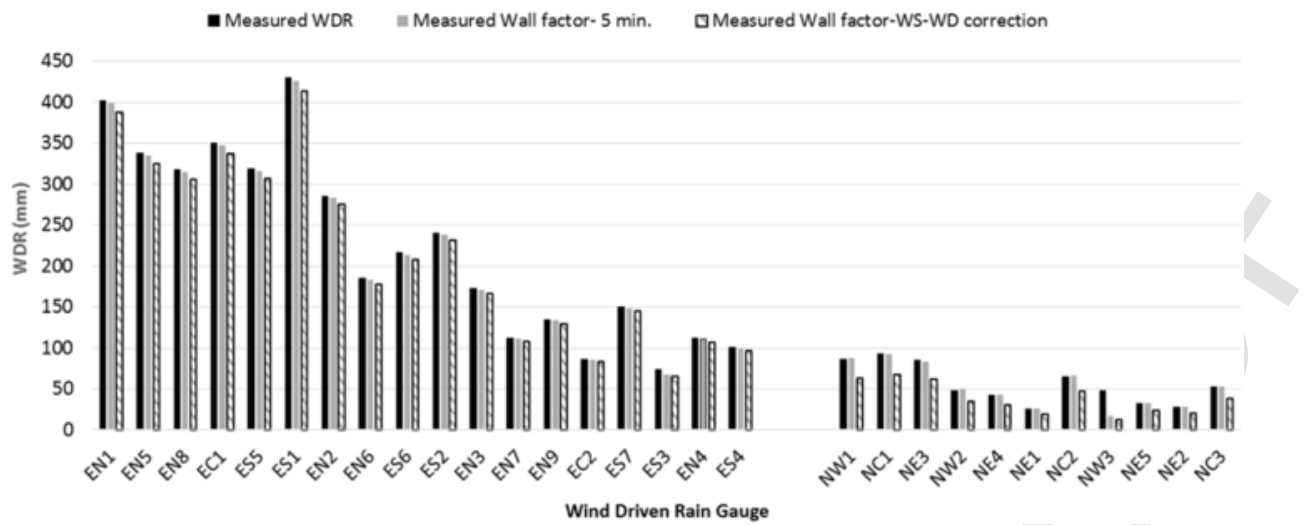

Fig. 21. Comparison of WDR between measurements and calculations by ISO model with wind adjustments and wall factors based on 5-min data.

power law wind profile with a suburban terrain mean speed exponent.

The semi-empirical ISO model is then used to calculate the WDR on façade and the calculation is compared to measurements. It is found that:

- The ISO model overestimates the WDR amount at $93 \%$ of the monitored locations (26 out of 28) and slightly underestimates for the remaining $7 \%$ (2 out of 28 ) locations. The overestimation can be as high as more than two times for locations typically at $2.4 \mathrm{~m}$ below the roofline.

- The significant overestimation by the ISO model is mainly due to wall factors suggested by ISO standard, which are generally greater than what has been measured and are lack of variation over the façade surface. The ISO standard only suggests 2 wall factors for a multi-storey building with a low-sloped roof. Nevertheless, ISO standard provides conservative values.

- The application of measured wall factors in ISO model significantly improved the calculation. The discrepancy between calculated and measured WDR is reduced to $21 \%$ for the East façade and with a maximum of $94 \%$ for the North façade.

- Further analysis shows that the difference in wind conditions (wind speed and wind direction) between airport and the site is the main contributor to the discrepancy that still exists. This difference can be accounted for by adjusting the hourly wind speed and filtering the hourly wind direction or calculate wall factors using 5-min instead of hourly averaged wind data measured on site.

- By adjusting the hourly wind speed and wind direction airport data, the discrepancy can be reduced to about $4 \%$ for the East façade and to $27 \%$ for the North façade;

- By using 5-min wall factors, the discrepancy can be reduced to less than $1 \%$ for the East façade and $1.5 \%$ for the North façade.

In conclusion, semi-empirical ISO model can be used to estimate WDR façade with accuracy if proper procedures measuring on-site wind conditions and calculating spatial distribution correction factors using high-resolution measurements are followed. The accurate quantification of WDR on façade is essential for designing and modelling durable building envelopes. It is recommended that:

- The procedure followed in this study to verify the on-site wind speed measurements by anemometer installed on the rooftop through comparison with measurements obtained from nearby weather station and measurements obtained from wind-tunnel should be implemented for proper on-site wind speed measurements. Should discrepancies exist, corrections through comparison with wind-tunnel measurements may be necessary.

- By neglecting building specific features a significant overestimation or underestimation may be encountered when using the ISO standard. However, the semi-empirical ISO model can provide accurate estimation of WDR on façade if more detailed wall factors are provided. High-resolution measurements at 5-min or 10-min intervals should be made available for the calculation of wall factors, which will help compensate the difference in wind conditions between airport weather station and the site, and consequently greatly improve the accuracy of ISO WDR model.

\section{Uncited references}

Gualtieri and Sessi, 2011; Turner, 1994.

\section{Acknowledgements}

Financial supports received from NSERC Strategic Research Network for Engineered Wood-based Building Systems (NEWBuildS), BC Housing, and the Faculty of Engineering and Computer Science of Concordia University are acknowledged.

\section{References}

Abuku, M., Blocken, B., Nore, K., Thue, J.V., Carmeliet, J., Roels, S., 2009. On the validity of numerical wind-driven rain simulation on a rectangular low-rise building under various oblique winds. Build. Environ. 44 (3), 621-632.

Blocken, B., Carmeliet, J., 2004. A review of wind-driven rain research in building science. J. Wind Eng. Ind. Aerod. 92 (13), 1079.

Blocken, B.J.E., Carmeliet, J.E., 2005. Guidelines for wind, rain and wind-driven rain measurements at test-building sites. In: Proceedings of the 7th Symposium on Building Physics in the Nordic Countries: Reykjavik, pp. 530-537.

Blocken, B., Carmeliet, J., 2005. High-resolution wind-driven rain measurements on a low-rise building — experimental data for model development and model validation. J. Wind Eng. Ind. Aerod. 93 (12), 905-928, 2005.

Blocken, B., Carmeliet, J., 2006. On the accuracy of wind-driven rain measurements on buildings. Build. Environ. 41 (12), 1798.

Blocken, B., Carmeliet, J., 2006. Validation of CFD simulations of wind-driven rain on a low-rise building façade. Build. Environ. 42 (7), 2530-2548.

Blocken, B., Carmeliet, J., 2007. Validation of CFD simulations of wind-driven rain on a low-rise building façade. Build. Environ. 42 (7), 2530.

Blocken, B., Carmeliet, J., 2010. Overview of three state-of-the-art wind-driven rain assessment models and comparison based on model theory. Build. Environ. 45 (3), 691-703.

Blocken, B., Abuku, M., Roels, S., Carmeliet, J., 2009. Wind-driven rain on building facades: some perspectives. EACWE 5, 19-23.

Blocken, B., Abuku, M., Nore, K., Briggen, P.M., Schellen, H.L., Thue, J.V., Roels, S., Carmeliet, J., 2011. Intercomparison of wind-driven rain deposition models based on two case studies with full-scale measurements. J. Wind Eng. Ind. Aerod. 99 (4), 448-459.

Chiu, V., Ge, H., Stathopoulos, T., 2015. Overhang effect on reducing wind-driven rain for a mid-rise building. In: Proceedings of the 6th International Building Physics Con- 
ference: Building Physics for a Sustainable Built Environment. Turin, Italy. June 14-17.

Foroushani, S., Ge, H., Naylor, D., 2013. Effects of roof overhangs on wind-driven rain wetting of a low-rise cubic building: a numerical study. J. Wind Eng. Ind. Aerod. 125, 38-51.

Ge, H., Deb Nath, U.K., Chiu, V., 2017. Field measurements of wind-driven rain on midand high-rise buildings in three Canadian regions. Build. Environ. 116, 228-245.

Ge, H., Chiu, V., Stathopoulos, T., 2017. Effect of overhang on wind-driven rain wetting of facades on a mid-rise building: field measurements. Build. Environ. 118, 234-250.

Gualtieri, G., Sessi, S., 2011. Comparing methods to calculate atmospheric stability-dependent wind speed profiles: a case study on costal location. Renew. Energy 36, 2189-2204.

Huang, S.H., Li, Q.S., 2010. Numerical simulations of wind-driven rain on building envelopes based on Eulerian multiphase model. J. Wind Eng. Ind. Aerod. 98 (12), 843-857.

International Standard Organization (ISO), 2009. Hygrothermal Performance of Buildings-Calculation and Presentation of Climatic Data-Part3: Calculation of a Driving Rain Index for Vertical Surfaces from Hourly Wind and Rain Data. ISO 15927-3, 2009.

Krpan, R., Ge, H., 2014. Wind-driven rain on the walls of buildings in Metro Vancouver: parameters for rain penetration testing. In: Proceeding of 14th Canadian Conference on Building Science and Technology, Oct., Toronto. pp. 277-286.

Kubilay, A., Derome, D., Blocken, B., 2013. CFD simulation and validation of wind-driven rain on a building facade with an Eulerian multiphase model. Build. Environ. 61, 69-81.

Kubilay, A., Derome, D., Blocken, B., Carmeliet, J., 2014. Numerical simulations of wind-driven rain on an array of low-rise cubic buildings and validation by field measurements. Build. Environ. 81, 283-295.

Kubilay, A., Derome, D., Blocken, B., Carmeliet, J., 2014. High-resolution field measurements of wind-driven rain on an array of low-rise cubic buildings. Build. Environ. 78, $1-13$.
Kubilay, A., Derome, D., Blocken, B., Carmeliet, J., 2015. Numerical modeling of turbulent dispersion for wind-driven rain on building facades. Environ. Fluid Mech. 15 (1), 109-133.

Kubilay, K., Derome, D., Blocken, B., Carmeliet, J., 2015. Wind-driven rain on two parallel wide buildings: field measurements and CFD simulations. J. Wind Eng. Ind. Aerod. 146, 11-28.

Kubilay, A., Derome, D., Carmeliet, J., 2017. Analysis of time-resolved wind-driven rain on an array of low-rise cubic buildings using large eddy simulation and an Eulerian multiphase model. Build. Environ. 114, 68-81.

Kubilay, K., Carmeliet, J., Derome, D., 2017. Computational fluid dynamics simulations of wind-driven rain on a mid-rise residential building with various types of facade details. J. Build. Perform. Simulat. 10 (2), 125-143.

Kumaran, K., Sanders, C., 2008. IEA Annex 41, Final Report, Volume 3. Whole Building Heat, Air, Moisture Response - Boundary Conditions and Whole Building HAM Analysis. International Energy Agency.

Deb Nath, K.U., Chiu, V., Ge, H., 2015. Measurements of wind-driven rain on mid- and high-rise buildings in three Canadian regions. In: Proceedings of the 6th International Building Physics Conference: Building Physics for a Sustainable Built Environment. Turin, Italy. June 14-17.

Nore, K., Blocken, B., Petter Jelle, B., Thue, J.V., Carmeliet, J., 2007. A dataset of wind-driven rain measurements on a low-rise test building in Norway. Build. Environ. 42 (5), 2150-2165.

Pettersson, K., Krajnovic, S., Kalagasidis, A.S., Johansson, P., 2016. Simulating wind-driven rain on building facades using Eulerian multiphase with rain phase turbulence model. Build. Environ. 106, 1-9.

Stathopoulos, T., 1984. Design and fabrication of a wind tunnel for building aerodynamics. J. Wind Eng. Ind. Aerod. 16 (2-3), 361-376.

Turner, D.B., 1994. Workbook of Atmospheric Dispersion Estimates: an Introduction to Dispersion Modeling, second ed. CRC Press. 